\title{
Processability of wood fibre-filled thermoplastic composite thin-walled parts using injection moulding
}

\begin{abstract}
A review of research on injection-moulded wood fibre-filled thermoplastic composites is presented in this chapter. Brief description of injection-moulding compounding process (including drying and mixing and extrusion) as well as injection-moulding process itself is als presented. A review on wood fibre- reinforced thermoplastic composites is also reported. An in-depth discussion is presented on thin-part moulding and the formation of residual stresses, volumetric shrinkage and warpage using injection moulding for composite products. Simulation work and statistical analysis related to the topic are also reviewed. Finally, some ideas about further research on wood-filled thermoplastic composite are proposed.
\end{abstract}

Keyword: Wood polymer composites; Thin-walled part; Injection moulding; Residual stresses; Shrinkages; Warpage 